九州大学学術情報リポジトリ

Kyushu University Institutional Repository

\title{
Hydrograph Recession Analysis using Wavelet Transforms
}

Sujono, Joko

Laboratory of Drainage and Water Environment, Division of Regional Environment Science, Department of Bioproduction Environmental Science, Graduate School of Bioresource and Bioenvironmental Sciences, Kyushu University

Shikasho, Shiomi

Laboratory of Drainage and Water Environment, Division of Regional Environment Science, Department of Bioproduction Environmental Science, Faculty of Agriculture, Kyushu University

Hiramatsu, Kazuaki

Laboratory of Drainage and Water Environment, Division of Regional Environment Science,

Department of Bioproduction Environmental Science, Faculty of Agriculture, Kyushu University

https://doi.org/10.5109/24406

出版情報: 九州大学大学院農学研究院紀要. 45 (2)，pp.557-564，2001-02-28. Kyushu University バージョン：

権利関係 : 


\title{
Hydrograph Recession Analysis using Wavelet Transforms
}

\author{
Joko Sujono*, Shiomi Shikasho and Kazuaki Hiramatsu \\ Laboratory of Drainage and Water Environment, Division of Regional Environment Science, \\ Department of Bioproduction Environmental Science, Faculty of Agriculture, \\ Kyushu University, Fukuoka 812-8581, Japan \\ (Received October 31, 2000 and accepted November 10, 2000)
}

\begin{abstract}
A technique for determining hydrograph recession characteristics is presented based on the wavelet transforms analysis. Like a signal, a flood hydrograph can be decomposed into a number of wavelet components. By using the wavelet component values in the form of wavelet maps, the recession characteristics such as a recession constant and a cut-off frequency are easily determined. The technique is demonstrated on three catchments ranging from small to large catchment areas at eastern New South Wales, Australia. The proposed method gives promising results and minimizes a number of problems associated with hydrograph recession analysis.
\end{abstract}

\section{INTRODUCTION}

Hydrograph recession analysis has long been a topic of research in hydrology. The recession curve contains valuable information about natural storage properties and aquifer characteristics. Recession analysis has been applied in many areas including low flow forecasting to benefit the management of irrigation, water supply allocation and waste dilution scheme (Tallaksen, 1995). Hydrograph recession characteristics are required for hydrological modeling such as a unit hydrograph method.

A number of techniques has been developed and used for analyzing the hydrograph recession curve. Semi-logarithmic plot of the recession curve (discharge on the logarithmic scale) is useful for investigating the components of hydrograph recession and for determining the end of surface runoff (Pilgrim and Cordery, 1993). On the semi-logarithmic plots, the recession curve can be approximated by three straight lines (Linsley et al., 1958). The end of direct flow (surface flow and interflow) is generally assumed to be the point of intersection of the two lowest lines, since the different slopes represent different flow components. Often, however, the transition from one line to the next line is so gradual, hence it is difficult to select the points of change in slope as well as the slope itself as shown in Fig. la.

Another method for analyzing the recession curve can also be carried out by plotting the recession parts on semi-logarithmic plots. Instead of plotting directly discharge data on the logarithmic scale, discharge ratio values $\left(Q_{0} / Q\right)$ are used as given in Fig. 1b. $Q_{0}$ is

\footnotetext{
* Laboratory of Drainage and Water Environment, Division of Regional Environment Science, Department of Bioproduction Environmental Science, Graduate School of Bioresource and Bioenvironmental Sciences, Kyushu University

* Corresponding author (E-mail: jsujono@agr.kyushu-u.ac.jp)
} 

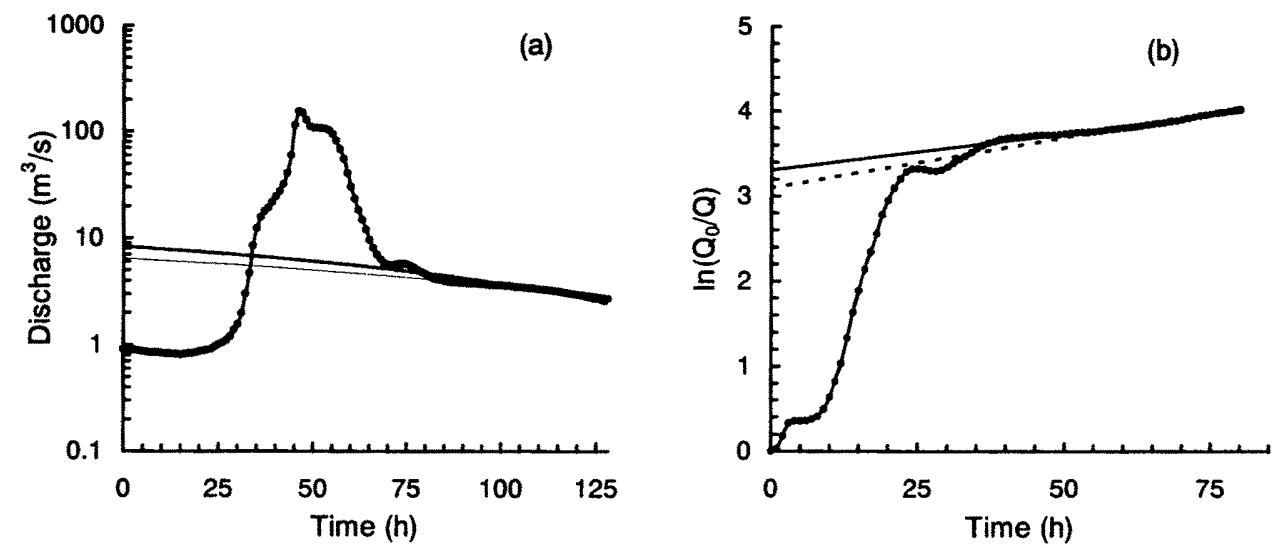

Fig. 1. Graphical methods for estimating (a) recession constant $K$ and (b) cut-off frequency $f_{c}$

initial flow and $Q$ is flow at $t$ time after $Q_{0}$. Hino and Hasebe (1984) used this approach to determine the cut-off frequency of the component separation of hourly hydrologic data by finding the slope of the recession curve. As a graphical method, the method has also high level of subjectivity, as the slope is not easily defined.

In this paper, a new technique for determining hydrograph recession characteristics is presented based on the wavelet transform analysis. By analyzing the wavelet maps, the recession characteristics, hopefully, can be determined more accurate and less subjective.

\section{METHODS AND DATA USED}

\section{Recession Curve}

The hydrograph recession curve represents withdrawal of water from storage within the catchment. The shape of the recession curve can be expressed by (e.g. Hino and Hasebe, 1984; Nathan and McMahon, 1990):

$$
Q_{t}=Q_{0} \exp (-\alpha t) \quad \text { or } \quad Q_{t}=Q_{0} \exp \left(-\frac{t}{T_{c}}\right)
$$

where $Q_{l}$ is the discharge at time $t, Q_{0}$ is the initial discharge, $\alpha$ is a constant or it is also called a cut-off frequency $\left(f_{c}\right)$ and $T_{c}$ is a recession period; the term $\exp (-\alpha)$ may be replaced by $K$ which is called a recession constant. The above equation is then written in the following form:

$$
Q_{i}=Q_{0} K^{t} \text {. }
$$

The relationship between the cut-off frequency $\left(f_{c}\right)$ and the recession constant $(K)$ can be written in the following form:

$$
K=e^{-f_{r}} \quad \text { or } \quad f_{c}=-\ln (K) \text {. }
$$

Typical value of hourly recession constant of groundwater flow component for 
catchments ranging from 300 to $16,000 \mathrm{~km}^{2}$ in eastern Australia and United States is 0.998 $\left(f_{c}=0.002\right)$ (Pilgrim and Cordery, 1993).

\section{Wavelet Transforms}

Any arbitrary signal $f(x)$ can be decomposed into an infinite summation of wavelets at different levels according to the wavelet expansion as the following (Newland, 1993):

$$
f(x)=\sum_{j=-\infty}^{\infty} \sum_{k=-\infty}^{\infty} c_{j, k} W\left(2^{j} x-k\right)
$$

where $c_{j, k}$ are the wavelet coefficients, $W\left(2^{j} x-k\right)$ is wavelet function and $k$ is integer. The integer $j$ describes different level of wavelets. Those coefficients of a number wavelet functions such as Daubechies, Symlet can be found in some textbooks (e.g. Sakakibara, 1995; Vidakovic, 1999).

By assuming $f(x)$ is zero outside the interval $0 \leq x<1$, scaling function and wavelet function are wrapped around the interval, the wavelet expansion of $f(x)$ in $0 \leq x<1$ can be written as:

$$
f(x)=a_{0}+\sum_{j} \sum_{k} a_{2^{j}+k} W\left(2^{j} x-k\right),
$$

where $a_{0}$ is the wrapped scaling function (the lowest wavelet) that is equal to the average value of signal $f(x), W\left(2^{j} x-k\right)$ are wrapped wavelet functions. The integer $j$ describes different levels of wavelets, starting with $j=0$; the integer $k$ covers the number of wavelets in each level, so that it covers the range $k=0$ to $\mathscr{2}^{j}-1$.

The mean-square value of $f(x)$ can be calculated by squaring both sides of the Eq. (5) and integrating over the interval $0 \leq x<1$. The final result can be expressed in the following form (Newland, 1993):

$$
\int_{0}^{1} f^{2}(x) d x=a_{0}^{2}+\sum_{j} \sum_{k} a_{2^{j}+k}^{2}\left(\frac{1}{2^{j}}\right) .
$$

Writing out the first few terms of the double summation, the mean square of $f(x)$ can be written as:

$$
\int_{0}^{1} f^{2}(x) d x=a_{0}^{2}+a_{1}^{2}+\frac{1}{2}\left(a_{2}^{2}+a_{3}^{2}\right)+\frac{1}{4}\left(a_{4}^{2}+a_{5}^{2}+a_{6}^{2}+a_{7}^{2}\right)+\frac{1}{8}\left(a_{8}^{2}+a_{9}^{2}+\cdots+a_{15}^{2}\right)+\cdots .
$$

Eq.7 shows that the mean square of $f(x)$ is distributed between different wavelet levels and between different wavelets within each level. Also, Eq. 7 can be illustrated graphically by a three-dimensional plot called mean-square wavelet map. Instead of using wavelet levels in drawing the map, the use of their frequency may be more appropriate for analyzing the recession curve behavior. The centered frequency in each level may be computed by using the following expression:

$$
f=\frac{2^{j} f_{s}}{N}
$$

where $f$ is centered frequency, integer $j$ is wavelet level, $f_{s}=1 / \Delta t, \Delta t$ is unit time interval, and $N$ is length of the data.

\section{Data Used}

The proposed technique for determining hydrograph recession characteristics is applied to three catchments at eastern New South Wales (NSW), Australia. The catchment areas range from $39 \mathrm{~km}^{2}$ to $2,670 \mathrm{~km}^{2}$. Details of the catchment characteristics such 
Table 1. Catchment characteristics used in the study

\begin{tabular}{clrrr}
\hline Number & \multicolumn{1}{c}{ Gauging Station } & $\begin{array}{r}\text { Area } \\
\left(\mathrm{km}^{2}\right)\end{array}$ & $\begin{array}{r}\text { MAR } \\
(\mathrm{mm})\end{array}$ & $\begin{array}{c}\text { MAF } \\
\left(\mathrm{m}^{3} / \mathrm{s}\right)\end{array}$ \\
\hline 203012 & Byron Creek at Binna Burra & 39 & 1830 & 165 \\
204015 & Boyd River at Broadmeadows & 2670 & 860 & 555 \\
416008 & Beardy River at Haystack & 866 & 840 & 236 \\
\hline
\end{tabular}

as catchment area, mean annual rainfall (MAR), mean annual flood (MAF) are given in Table 1. For each catchment, three floods event of hourly interval are selected for the analysis. The data were extracted from Pinneena version 6.1 published by the Department of Land and Water Conservation, NSW (1999).

\section{RESULTS AND DISCUSSION}

By using the wavelet component values in the form of wavelet maps, the recession characteristics were analyzed. Fig. 2 to Fig. 4 show the mean-square value maps together with their original signals (flood event hydrographs) for three catchments studied. The figures provide valuable information of the recession curve behavior. Change in the recession line affect to the mean square values of the signal characterized by change of the wavelet maps. As the baseflow component has a recession time much longer than other components (surface flow and interflow), thus the baseflow component has the lowest frequency compared with the other components.

All the wavelet maps show that the lowest frequencies can easily be distinguished from the others. As a result, the cut-off frequency or the recession constant can be determined more objective than the existing methods (semi-logarithmic plot methods). Moreover, the end of the direct flow $T_{b}^{\prime}$ may be determined by looking at the time scale where the mean-square values reach maximum.

Table 2. shows the cut-off frequency values for all data estimated both using wavelet transforms and semi-logarithmic plot method. The table gives clear indication that the semi-logarithmic plot or the graphical method has high level of subjectivity in determining the recession characteristics, whereas the wavelet transforms produces exact values. Since the accuracy of the cut-off frequency computed using the wavelet transforms depends on the length $N$ of the data used (see Eq. 8), more accurate results may be obtained by using the longer data. In case of flood events analysis, smaller time interval may be required.

\section{CONCLUSION}

A new technique for determining the hydrograph recession characteristics was successfully applied to three catchments at eastern New South Wales, Australia. The recession constant, the cut off frequency and the end of surface runoff of a flood hydrograph are easily determined using the proposed technique. Further application of the technique to other catchments and study of their wavelet maps behavior are needed to give more definite results of the hydrograph recession characteristics. 

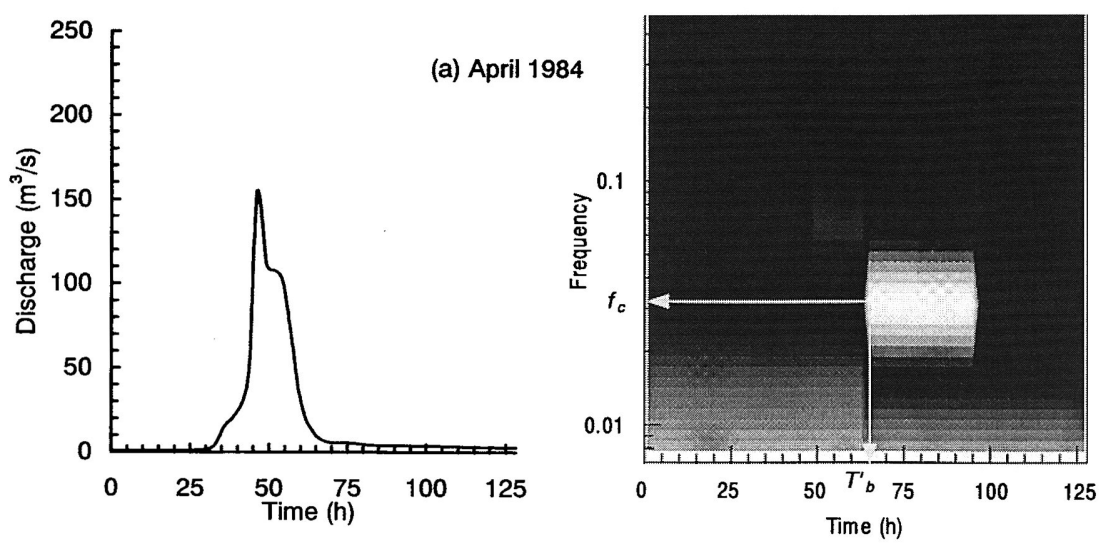

Colormap Key

$55+$

50 to 55

45 to 50

40 to 45

35 to 40

30 to 35

25 to 30

20 to 25

15 to 20

10 to 15

5 to 10

0 to 5
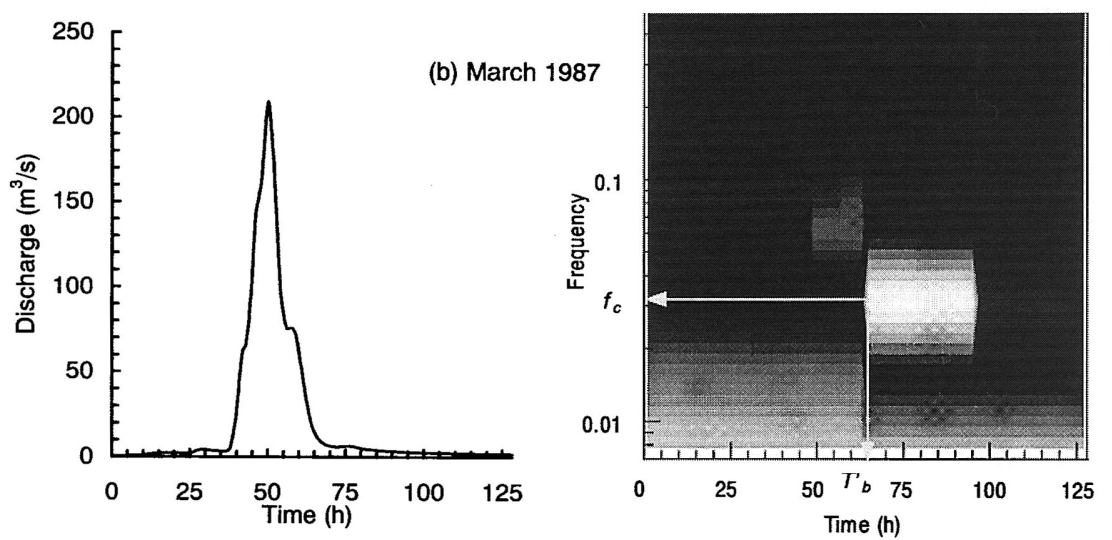

Colormap Key

$88+$

80 to 88

72 to 80

64072

56 to 64

48 to 56

40 to 48

32 to 40

24 to 32

16 to 24

8 to 16

0 to 8
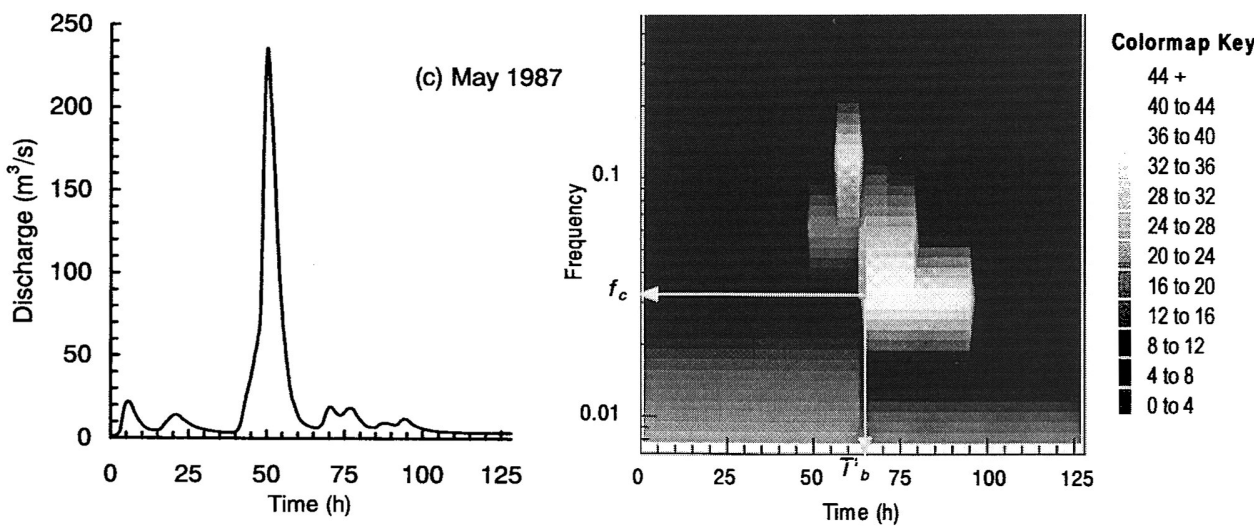

Fig. 2. Flood events and their wavelet maps of station $203012\left(\mathrm{~A}=39 \mathrm{~km}^{2}\right)$ (a) event April 1984, (b) event March 1987 and (c) event May 1987 

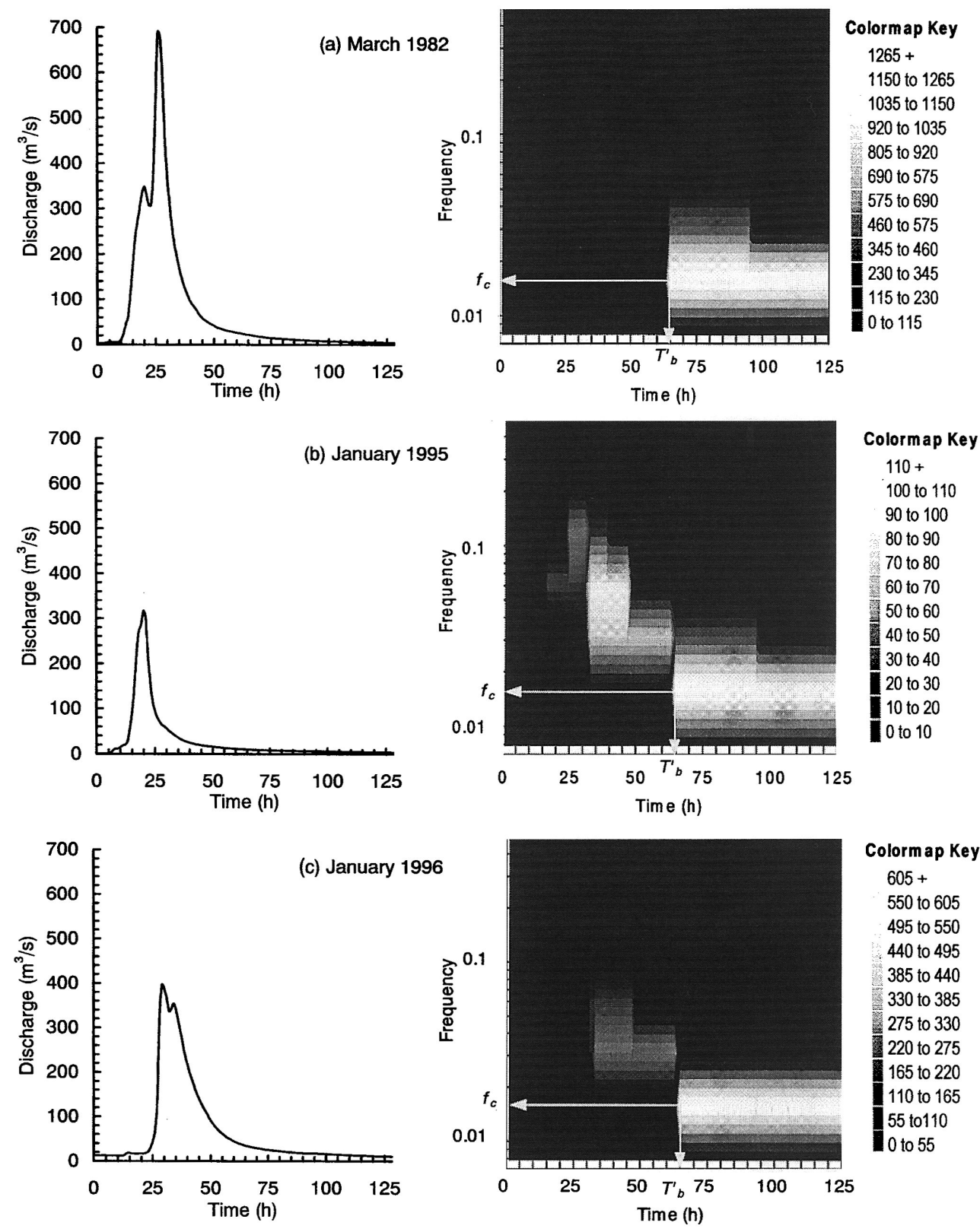

Fig. 3. Flood events and their wavelet maps of station $416008\left(A=866 \mathrm{~km}^{2}\right)$ (a) event March 1982, (b) event January 1995 and (c) event January 1996 

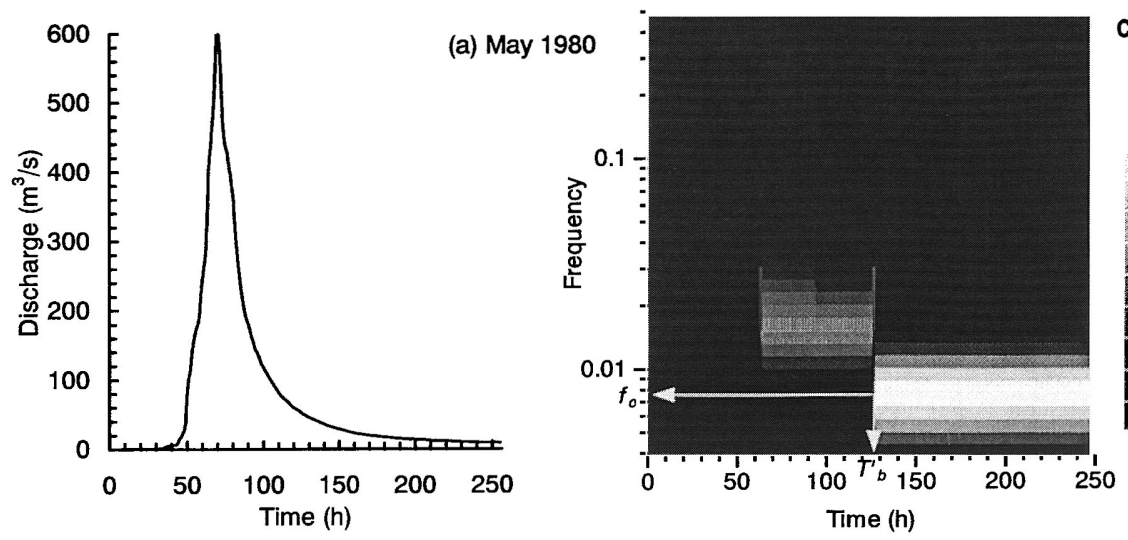

Colormap Key

$1925+$

1750 to 1925

1575 to 1750

1400 to 1575

1225 to 1400

1050 to 1225

875 to 1050

700 to 875

525 to 700

350 to 525

175 to 350

0 to 175
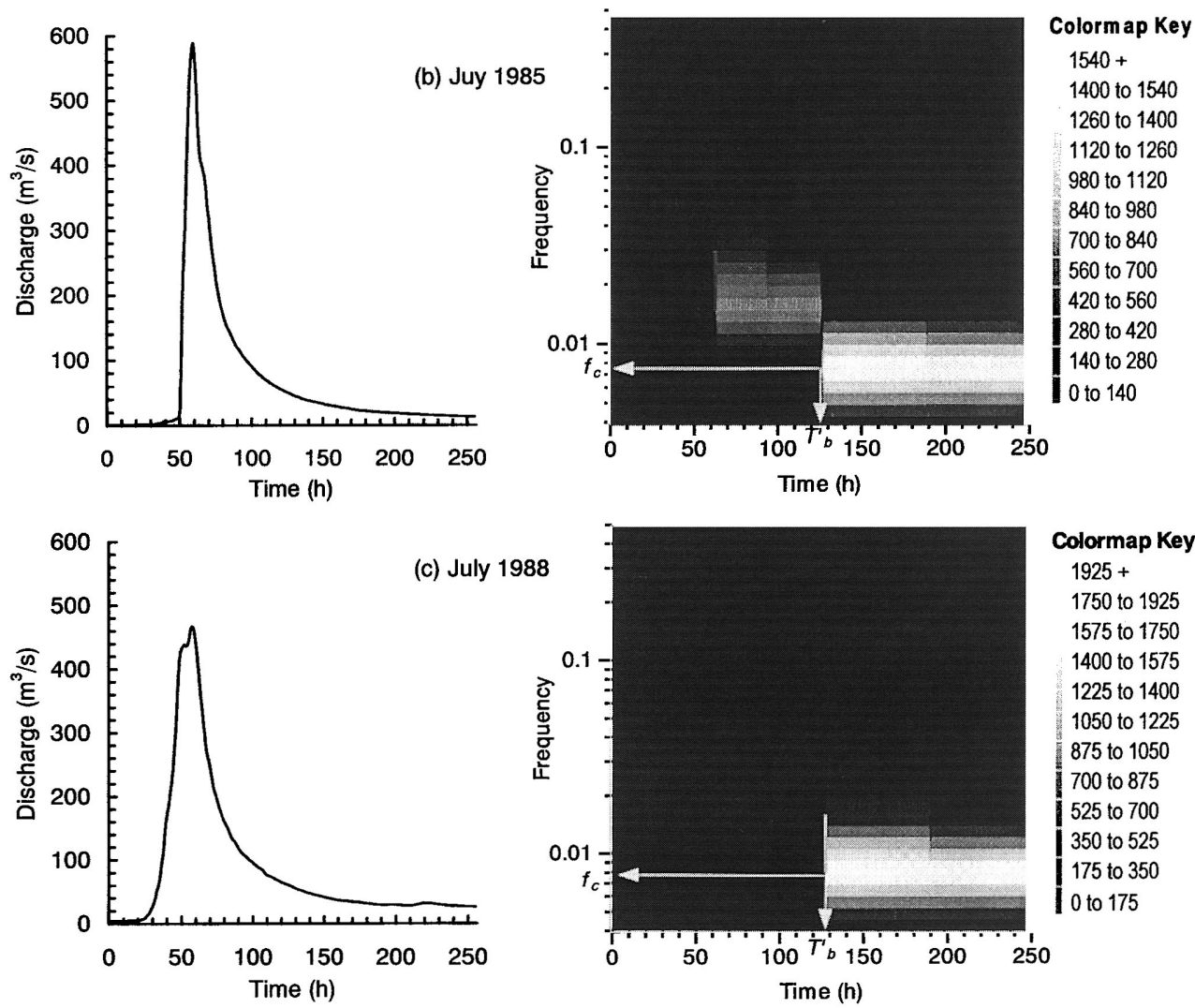

Fig. 4. Flood events and their wavelet maps of station $204015\left(\mathrm{~A}=2670 \mathrm{~km}^{2}\right)$ (a) event May 1980 (b) event July 1985, and (c) event July 1988 
Table 2. Cut-off frequency $f_{c}$ using different methods

\begin{tabular}{llcc}
\hline Station & Flood event & Graphical method & Proposed method \\
\hline \multirow{2}{*}{203012} & March 1984 & $0.0086-0.0120$ & 0.0313 \\
& March 1987 & $0.0112-0.0311$ & 0.0313 \\
\multirow{2}{*}{204015} & May 1987 & $0.0315-0.1042$ & 0.0313 \\
& May 1980 & $0.0094-0.0100$ & 0.0078 \\
& July 1985 & $0.0072-0.0089$ & 0.0078 \\
& July 1988 & $0.0023-0.0146$ & 0.0078 \\
& March 1982 & $0.0262-0.0310$ & 0.0156 \\
& January 1995 & $0.0161-0.0293$ & 0.0156 \\
& January 1996 & $0.0150-0.0184$ & 0.0156 \\
\hline
\end{tabular}

\section{REFERENCES}

Department of Land and Water Conservation 1999 Pinneena 6 Series CD. New South Wales, Australia. Hino, M. and M. Hasebe 1984 Identification and prediction of nonlinear hydrologic systems by the filter-separation autoregressive (AR) method: extension to hourly hydrologic data. Journal of Hydrology, 68: 181-210

Linsley, R. K., M. A. Kohler and J. L. H. Paulhus 1958 Hydrology for Engineers, McGraw-Hill, New York, pp. 151-155

Nathan, R. J. and T. A. McMahon 1990 Evaluation of automated techniques for base flow and recession analyses. Water Resources Research, 26(7): 1465-1473

Newland, D. E. 1993 An Introduction to Random Vibrations, Spectral and Wavelet Analysis. Longman, Singapore, pp. 295-353

Pilgrim, D. H. and I. Cordery 1993 Flood Runoff. In "Handbook of Hydrology", ed. by D. R. Maidment, McGraw-Hill, New York, pp. 9.4-9.6

Sakakibara, S. 1995 Beginners' Guide to Wavelet. Tokyo Denki University Publications, Tokyo (in Japanese)

Tallaksen, L. M. 1995 A review of baseflow recession analysis. Joumal of Hydrology, 165: 349-370

Vidakovic, B. 1999 Statistical Modeling by Wavelets. John Wiley \& Sons, Inc., New York, pp. 81-87 